\title{
Maladaptive Variants of Adaptive Traits and Bloated Specific Factors
}

\author{
Joshua R. Oltmanns and Thomas A. Widiger \\ University of Kentucky
}

\begin{abstract}
The five-factor model of personality disorder (FFMPD) hypothesizes that the traditionally adaptive five-factor model (FFM) poles (e.g., agreeableness) include maladaptive variants. However, "bloated specific factors" (BSFs), which are artifactual factors that emerge when a specific facet of a broader construct is over-represented, complicate research on the maladaptive variants. Twentyfive sets of factor analyses are completed herein demonstrating that items from maladaptive trait facet scales form BSFs when over-represented in factor analyses with other FFM indicators, separating from the higher-order domains in which they were originally located. These results held in 23 of 25 cases. Ensuring balanced collections of scales representing constructs would help researchers avoid BSFs. The implications of BSFs for future research on personality structure are discussed.
\end{abstract}

\section{Keywords}

maladaptive; adaptive; personality traits; bloated specific factors; five-factor model

The predominant model of general personality structure is arguably the Five Factor Model (FFM), consisting of the five broad domains of neuroticism, extraversion, openness, agreeableness, and conscientiousness (John, Naumann, \& Soto, 2008). A growing empirical base of evidence has also demonstrated that the FFM accounts well for maladaptive personality traits, as represented within the personality disorders section of the American Psychiatric Association's (APA) Diagnostic and Statistical Manual of Mental Disorders (DSM-5; APA, 2013; Widiger, Gore, Crego, Rojas, \& Oltmanns, 2017). The five-factor model of personality disorder (FFMPD) hypothesizes that all ten poles of the FFM include maladaptive variants (Samuel, 2011; Trull, 2012; Widiger \& Trull, 2007). It is straightforward to demonstrate an association of neuroticism, introversion, low openness,

Correspondence should be addressed to Joshua R. Oltmanns, Department of Psychology, University of Kentucky, 111-D Kastle Hall, Lexington, KY, 40506. jroltmanns@uky.edu.

Publisher's Disclaimer: This is a PDF file of an unedited manuscript that has been accepted for publication. As a service to our customers we are providing this early version of the manuscript. The manuscript will undergo copyediting, typesetting, and review of the resulting proof before it is published in its final citable form. Please note that during the production process errors may be discovered which could affect the content, and all legal disclaimers that apply to the journal pertain.

Open Practices

The data and syntax are available at: https://osf.io/rzg4a/

J.R.O and T.A.W. both conceptualized and designed the study and wrote the manuscript. J.R.O. administered data collection, prepared data, and conducted data analyses. 
antagonism (i.e., low agreeableness), and low conscientiousness with maladaptive personality functioning (Lynam \& Widiger, 2001), but the relationship of the other sides of these domains (i.e., low neuroticism, extraversion, high openness, agreeableness, and conscientiousness) with maladaptivity has been more problematic. It has in fact been largely rejected by some (Krueger et al., 2011; Williams \& Simms, in press). There are a number of reasons that it is difficult to document the relationship of low neuroticism, high extraversion, openness, agreeableness, and conscientiousness with maladaptive functioning (Widiger \& Crego, in press). Explored in the current study is the potential occurrence of a bloated specific factor (BSF; Cattell \& Tsujioka, 1964), which appears to have gone unrecognized in recent FFMPD research.

The FFMPD hypothesis is formally recognized within the fifth edition of the APA diagnostic manual (DSM-5; APA, 2013) and within the proposals for the 11th edition of the WHO diagnostic manual (ICD-11; International Advisory Group for the Revision of ICD-10, 2011). The DSM-5 includes a five-domain dimensional trait model within Section III, which is for emerging measures and models. The domains consist of negative affectivity, detachment, psychoticism, antagonism, and disinhibition. As stated in DSM-5, "these five broad domains are maladaptive variants of the five domains of the extensively validated and replicated personality model known as the 'Big Five,' or the Five Factor Model of personality" (APA, 2013, p. 773). Proposed for ICD-11 is a comparable trait model, consisting of negative affective, detachment, dissocial, disinhibition, and anankastic (Tyrer, Reed, \& Crawford, 2015). These domains are likewise aligned with the FFM: "Negative Affective with neuroticism, Detachment with low extraversion, Dissocial with low agreeableness, Disinhibited with low conscientiousness and Anankastic with high conscientiousness" (Mulder, Horwood, Tyrer, Carter, \& Joyce, 2016, p. 85).

However, a notable feature of both the DSM-5 and ICD-11 maladaptive trait models is that they are largely unipolar with respect to their structure. As expressed in DSM-5, "There are healthy, adaptive, and resilient personality traits identified as the polar opposite of these traits" (APA, 2013, p. 773); more specifically, "emotional stability, extraversion, lucidity, agreeableness, and conscientiousness" (APA, 2013, p. 773). The same point largely applies to the ICD-11 trait model proposal (albeit with one important exception, for compulsivity being opposite to disinhibition; Mulder et al., 2016).

FFMPD scales have been developed that assess for maladaptive variants of low neuroticism, high extraversion, openness, agreeableness, and conscientiousness (i.e., the poles of the FFM generally understood as being adaptive; Bagby \& Widiger, 2018). For high openness there is (for instance) Odd-Eccentric, Aberrant Ideas, and Aberrant Perceptions from the Five Factor Schizotypal Inventory (FFSI; Edmundson, Lynam, Miller, Gore, \& Widiger, 2011); for high conscientiousness there is Perfectionism, Fastidiousness, Workaholism, and Ruminative Deliberation from the Five Factor Obsessive-Compulsive Inventory (FFOCI; Samuel, Riddell, Lynam, Miller, \& Widiger, 2012); for low neuroticism there is Invulnerability and Unconcern from the Elemental Psychopathy Assessment (EPA; Lynam et al., 2011) and Indifference from the Five-Factor Narcissism Inventory (FFNI; Glover, Miller, Lynam, Crego, \& Widiger, 2012); for high extraversion there is Authoritativeness from the FFNI and Excitement-Seeking and Domineering from the EPA; for high agreeableness there is 
Subservience and Self-Effacing from the Five Factor Dependency Inventory (FFDI; Gore, Presnall, Lynam, Miller, \& Widiger, 2012) and Timorousness from the Five Factor Avoidant Assessment (FFAvA; Lynam, Loehr, Miller, \& Widiger, 2012). Empirical support for the FFM locations for all of these scales was provided within the initial validation studies (e.g., Edmundson et al., 2011; Lynam et al., 2011, 2012; Glover et al., 2012; Gore et al., 2011; Samuel et al., 2012) and subsequent cross-validation studies (Bagby \& Widiger, 2018).

However, there are certainly failures to find these expected relationships for some FFMPD and comparable scales (e.g., Berghuis, Kamphuis, \&Verheul, 2012; Crego, Oltmanns, \& Widiger, 2018; Watson, Clark, \& Chmielewski, 2008). Berghuis et al. reported that while interpersonal deficits loaded on FFM introversion and antagonism factors, self-deficit scales formed their own independent factor. Watson et al. reported maladaptive variants for four of the five FFM domains, but their schizotypal oddity scales failed to load on the FFM openness factor, separating to form their own independent factor. Crego et al. reported that most of the FFMPD scales loaded on the expected FFM factors, but FFMPD Gullibility and Subservience did not load on agreeableness, separating to form their own distinct factor. There are multiple reasons for such failures. One reason, of course, is that the hypothesis that there are maladaptive variants of high agreeableness, extraversion, conscientiousness, openness, and low neuroticism is incorrect (Krueger et al., 2011; Williams \& Simms, in press). Another possibility is simply that it is considerably more difficult to obtain a positive relationship of a maladaptive trait with an adaptive trait than it is to demonstrate a positive relationship of a maladaptive trait with another maladaptive trait (Widiger \& Crego, in press). However, explored in the current study is a further possible explanation: bloated specific factors, which Crego et al. suggested as an explanation for their aberrant findings for FFMPD Subervience and Gullibility.

Factor analysis has been employed as an investigative tool in many studies of the relations between the FFM and maladaptive traits (e.g., Berghuis et al., 2012; Crego et al., 2018; Watson et al., 2008; Wright \& Simms, 2014). Factor analysis, however, is not a flawless approach to hypothesis testing (Lykken, 1971). One problem that can occur in the course of a factor analysis is the emergence of a bloated specific factor (BSF; Cattell \& Tsujioka, 1964). A BSF is formed when a specific facet of a broader construct is over-represented with scales or items (i.e., indicators) relative to the other indicators of the broader construct. When several specific and closely related indicators over-represent a particular facet of the broader construct, the specific, homogeneous indicators may bind together and emerge as their own, unique factor. While the BSF may then appear to be a construct separated entirely from the other facets, its separation is in fact artefactual. Cattell (1978) cautioned that in factor analysis, a factor "boasting high homogeneity is at once suspect" (p. 289).

One can readily separate even a clearly well-established facet of a broader construct by overrepresenting a facet of that broader construct within a factor analysis. DeYoung (2011) even suggested that one might be able to separate anxiousness from neuroticism:

Consider what would happen if one included 10 scales measuring different types of anxiety in a factor analysis with the 30 facets of the Big Five measured by the NEO PI-R. One would be likely to find a sixth factor for anxiety, in addition to the usual 
Neuroticism factor encompassing traits like depression, vulnerability, and selfconsciousness. This would be considered a bloated specific factor because the location of anxiety as a lower-level trait within Neuroticism is well established. (DeYoung, 2011, p. 718)

The present study examines whether BSFs can be created within each domain of the FFM, and specifically with respect to maladaptive variants of FFM domains that have been traditionally understood to be normal poles of the FFM (e.g., maladaptive variants of openness, agreeableness, and conscientiousness). We hypothesize that when several specific indicators of any FFM domain are included in a factor analysis with the 30 FFM facets, the specific indicators will separate from the FFM factors to load on their own unique factor (forming a BSF). However, if only a subset of these specific indicators is submitted to the analysis with the FFM domains, these indicators will load within their respective FFM factor.

\section{Method}

Procedure

Participants were recruited via http://Amazon.com's Mechanical Turk (MTurk). Participants were required to be currently in mental health treatment or have been in mental health treatment at some point in the past. There was not a way to ensure in an online data collection that the participants had in fact received clinical treatment. However, separate MTurk data collections (such as in the present study) tend to provide replicable percentages of reported clinical history (e.g., type of disorder and type of treatment; Oltmanns \& Widiger, in press), inconsistent with random or false reporting. MTurk data collections more generally show similar or even better reliability than samples collected using more traditional methods (Buhrmester, Talaifar, \& Gosling, 2018; Chandler \& Shapiro, 2016; Miller, Crowe, Weiss, Maples-Keller, \& Lynam 2017). Participants were compensated $\$ 1.00$ for completion of the questionnaires.

Missing data were imputed with the expectation maximization (EM) procedure. EM has been shown to create estimates of population parameters that are more accurate than substitution of mean values (Enders, 2006). The study was approved by the local university institutional review board. Analyses were not preregistered. However, the analytic plan is replicated 25 times over in the present study (once for each maladaptive scale). Data and syntax are available at: https://osf.io/rzg4a/.

\section{Participants}

Five hundred and thirty-four potential participants were recruited from MTurk. Persons were removed if they did not complete $80 \%$ of each measure $(n=117)$. Thirty-eight additional persons were excluded due to noncontent-based responding (described below).The final sample size was $N=379$ ( $M_{\text {age }}=35.4$ years, $S D=11.5$ years, $69 \%$ female). Thirty-eight percent were currently in mental health treatment, $12 \%$ in the past one month, $23 \%$ in the past one year, $14 \%$ in the past five years, $10 \%$ in the past ten years, and $3 \%$ outside the past ten years. Fifty-four percent were currently taking psychiatric medications, and $86 \%$ had taken psychiatric medications in the past. Participants reported receiving mental health 
treatment for a variety of conditions: Depression (85\%), anxiety (73\%), personality disorder (8\%), substance abuse (9\%), alcohol abuse (8\%), psychosis (5\%), and other (12\%), which participants provided in an additional text box, including: attention-deficit hyperactivity disorder, anger problems, Asperger's syndrome, obsessive-compulsive disorder, bipolar disorder, suicidal ideation, medication side effects, body dysmorphic disorder, grief, physical illnesses, eating disorder, post-traumatic stress disorder, intermittent explosive disorder, marital problems, panic disorder, schizoaffective disorder, social phobia, agoraphobia, and workplace stress. Participants reported seeing psychiatrists (64\%), psychologists (55\%), social workers (18\%), family therapists (21\%), and other (8\%), including: counselors, primary care physicians, nurses, and group therapy. Marital status consisted of $38 \%$ single, $34 \%$ married, $18 \%$ cohabiting, $10 \%$ divorced, and $1 \%$ widowed. Racial and ethnic backgrounds consisted of $83 \%$ white, $6 \%$ black/African-American, 5\% Hispanic/Latino, 3\% Asian, $1 \%$ American Indian or Alaska Native, and 1\% other.

\section{Measures of Adaptive FFM Traits}

International Personality Item Pool - NEO - 120 (Maples, Guan, Carter, \& Miller, 2014).-The IPIP-NEO-120 is a 120 -item version of the 300 -item IPIP-NEO (Goldberg et al., 2006) that measures the 30 facets of the FFM. It was developed using item-response theory to identify the items that provided the most information about personality. Items were rated on a scale from 1 (strongly disagree) to 5 (strongly agree) and were summed for 30 facet scores and five domain scores. Internal consistency ranged from $a=.71$ (Liberalism) to .88 (Self-Discipline), with a median of .78 .

Five-Factor Form (FFF; Rojas \& Widiger, 2014).-The FFF is a 30-item questionnaire for which each item assesses one of the 30 facets of the FFM. Items are rated on the following scale: 1 (Maladaptive Low), 2 (Low), 3 (Neutral), 4 (High), and 5

(Maladaptive High). Each item includes unique adjectives to describe the maladaptive low, low, high, and maladaptive high levels of each facet, with a neutral option in the middle. The FFF has shown convergent and discriminant validity with well-known measures of the FFM (Rojas \& Widiger, 2014, 2018). Items from each FFM domain were summed to create five domain scores. Internal consistency ranged from $a=.62$ (Openness) to .75 (Neuroticism), with a median of .71 .

Five-Factor Model Rating Form (FFMRF; Mullins-Sweatt Jamerson, Samuel, Olson, \& Widiger, 2006).-The FFMRF is a 30-item adjective checklist questionnaire that assesses 30 facets of the FFM. Each end of a scale is labeled with trait adjectives (e.g., "sociable, outgoing" on the high end versus "withdrawn, isolated" on the low end for the Gregariousness facet). In between the two adjectives, items are rated on the following scale: 1 (Extremely Low), 2 (Low), 3 (Neutral), 4 (High), and 5 (Extremely High). The FFMRF has shown convergent and discriminant validity with the NEO-PI-R (Mullins-Sweatt et al., 2006; Samuel, Mullins-Sweatt, \& Widiger, 2013). Internal consistency ranged from $a=.64$ (Agreeableness) to .79 (Conscientiousness), with a median of .70. 


\section{Measures of Maladaptive FFM Traits}

It is the intention of the current study to illustrate the occurrence of a BSF for each of the five poles of the FFM that are not traditionally considered to include maladaptive variants: extraversion, openness, agreeableness, conscientiousness, and low neuroticism. For a BSF to occur, there needs to be sufficiently similar (homogeneous) indicators that will indeed bind together. Obtaining a sufficient number of such scales for all of the FFM facets considered in the current study is not feasible. In addition, even if enough such scales could be obtained for a particular FFM facet, the administration of all such scales for all five domains would have been excessive for subject participation.

Therefore, in the current study, the analyses were conducted with respect to the items of maladaptive trait scales. In addition, to ensure that the results would not simply reflect the nuances or vagaries of any one particular scale, an extensive number of alternative maladaptive trait scales were administered (i.e., 25), allowing for 25 replications of results across multiple measures. Scales were selected from maladaptive measures of personality that were considered by the test authors to be associated with a respective domain of neuroticism, extraversion, openness, agreeableness, or conscientiousness. All items were rated on Likert-type response scales ranging from 1 (strongly disagree) to 5 (strongly agree). For clarification purposes, we refer to the maladaptive variant scales we use for demonstration as "MAL" scales hereafter.

Neuroticism.-Four MAL scales were selected to assess specific facets of low neuroticism: EPA Invulnerability ( 9 items, $a=.92$; mean interitem correlation $[\mathrm{MIC}]=.56$ ); EPA Self-Assurance ( 9 items, $\alpha=.87$; MIC $=.41$ ); FFNI Indifference ( 10 items, $\alpha=.94$; MIC $=.60$ ); and Triarchic Model of Psychopathy Boldness (TPM; Patrick, Fowles, \& Krueger, 2009; 19 items, $a=.89 ; \mathrm{MIC}=.30$ ).

Extraversion.-Four MAL scales were selected to assess specific facets of maladaptive high extraversion: Narcissistic Personality Inventory Leader ship/Authority (NPI; Corry et al., 2008; Raskin \& Terry, 1988; 9 items, $a=.92$; MIC $=.56$ ); FFNI Authoritativeness (Glover et al., 2012; 10 items, $a=.93$; mean inter-item correlation $[\mathrm{MIC}]=.58$ ); EPA Dominance (Lynam et al., 2011; 9 items, $\alpha=.89$; MIC = .47); and Computerized-Adaptive Test for Personality Disorders Domineering (CAT-PD; Simms et al., 2011; $\mathrm{a}=.86$; $\mathrm{MIC}=$. $51)$.

Openness.-Six MAL scales were selected to assess specific facets of maladaptive high openness: FFSI Aberrant Ideas Edmundson et al., 2011; 10 items, $a=.88$; MIC = .41); FFSI Odd-Eccentric ( 10 items, $a=.93$; MIC $=.55)$; FFSI Aberrant Perceptions $(10$ items, $a=$. 89 ; $\mathrm{MIC}=.45)$; CAT-PD Peculiarity ( 5 items, $a=.84$; MIC $=.51$ ); CAT-PD Fantasy $(6$ items, $a=.81 ; \mathrm{MIC}=.42)$; and PID-5 Eccentricity (13 items, $a=.95$; $\mathrm{MIC}=.61$ ).

Agreeableness.-Seven MAL scales were selected to assess specific facets of maladaptive high agreeableness: IPIP RD4 Dependence (Goldberg et al., 2006; 10 items, a $=.71 ; \mathrm{MIC}=.20$ ); FFDI Subservience (Gore et al., 2012; 10 items, $a=.89 ; \mathrm{MIC}=.45$ ); FFDI Self-Effacing (10 items, $a=.87$; MIC = .39); FFAvA Timorousness (Lynam et al., 
2012; 7 items, $a=.73 ;$ MIC $=.28$ ); Personality Inventory for DSM-5 Submissiveness (PID-5; Krueger, Derringer, Markon, Watson, \& Skodol, 2012; 4 items, $a=.83$; MIC $=.56$ ); IPIP-HEXACO Modesty (Goldberg et al., 2006; 10 items, $a=.87$; MIC = .40); and CAT-PD Submissiveness (6 items, $\mathrm{a}=.87$; MIC $=.53$ ).

Conscientiousness.-Four MAL scales were selected to assess specific facets of maladaptive high conscientiousness: CAT-PD Workaholism ( 6 items, $a=.89$; $\mathrm{MIC}=.56$ ); PID-5 Rigid Perfectionism (10 items, $a=.92$; MIC = .53); FFNI Acclaim-Seeking (Glover et al, 2012; 10 items, $a=.91 ;$ MIC $=.52$ ); and FFOCI Workaholism (Samuel et al., 2012; 10 items, $a=.84 ; \mathrm{MIC}=.34$ ).

Noncontent-Based Responding Scale-Five additional items were included to gauge attention. These items were scattered throughout the questionnaire. Example items include, "I have used a computer in the past two years" (reverse-keyed) and "I am president of the United States." Items were rated from 1 to 5 and scored such that higher scores indicated non-content based responding. Participants with a score of $12+$ were eliminated from the dataset $(n=38)$. There is no standardized cutoff point on this measure, but scorers above 12 are more likely to be responding carelessly to the items. The cutoff point does distinguish between carelessly responding to most items versus carelessly responding to one or two items.

\section{Analyses}

Thirty FFM facet total scores were calculated by summing the three corresponding facet scores from each FFM measure that was administered (e.g., the sum of the Gregarious scales from the FFF, FFMRF, and IPIP). This provides 30 FFM facet scores that serve as a more comprehensive and reliable measure of the FFM. MICs were calculated for each domain and ranged from MIC $=.23$ (openness) to .49 (neuroticism), with a median of .44 . It should be noted that including the maladaptive ranges of the FFF in the total scores for the FFM facets only serves to broaden the assessment of each FFM facet and therefore make the appearance of a bloated specific factor less likely.

Tests for the number of factors and exploratory factor analysis (EFA) were conducted in $\mathrm{R}$ statistical software (R Core Team, 2013). Parallel analysis (Horn, 1965) and Velicer's revised (2000) MAP test for the number of factors were conducted using the paran (Dinno, 2012) and paramap (O'Connor, 2017) packages, respectively, and EFA was conducted using the psych package (Revelle, 2017). Parallel analysis and the MAP test were used in the present study to evaluate the optimal number of factors to retain. These two methods have been empirically demonstrated as more accurate than other factor retention criteria such as the eigenvalue greater-than-one rule and the Scree test (Velicer, Eaton, \& Fava, 2000), and are relatively simple to compute (Dinno, 2012; Hayton, Allen, \& Scarpello, 2004; O’Connor, 2000; O’Connor, 2017; Revelle, 2017). Parallel analysis was conducted comparing the actual eigenvalues from each dataset to the mean eigenvalue of random comparison matrices 30 times the number of variables in the dataset and under a principal components framework, which is consistent with the development of parallel analysis and most of the research literature on the technique and can be used by factor analytic 
researchers to inform decisions on the number of factors (Velicer, Eaton, \& Fava, 2000). The differences in the accuracy of parallel analysis using various specifications (e.g., principal axis framework, mean or $95^{\text {th }}$ percentile random eigenvalue) appear modest with a large sample size (e.g., $>N=300$ ), uncorrelated or moderately correlated factors (i.e., $r=0$ or $r$ $=.50$ ), high factor loadings (i.e., $=\lambda=.70$ ), and a relatively larger number of indicators (i.e., 6) per factor (Green, Levy, Thompson, Lu, \& Lo, 2012), which are all characteristics of the present analyses.

Analyses were conducted separately for each MAL scale. Items from MAL scales were chosen by selecting the MAL scale items with the highest correlations with their respective FFM domains. This would make it more difficult for the BSFs to separate from the other factors, but it would also help avoid an artifactual separation secondary to relatively weaker items being used. Datasets were created consisting of one through ten items from a respective MAL scale, and the 30 FFM facet total scores. For example, for FFNI Indifference, ten datasets were created. The first dataset contained one FFNI Indifference item and the 30 FFM facets, the second dataset contained two FFNI Indifference items and the 30 FFM facets, the third dataset contained three FFNI Indifference items and the 30 FFM facets, and so forth until all ten FFNI Indifference items were included in a dataset with the 30 FFM facets. Parallel analysis and MAP tests were then conducted on each of the ten FFNI Indifference datasets to identify the recommended number of factors to extract from each dataset. After the number of factors was established, EFA was completed with the recommended number of factors. Factor loadings were then inspected for each solution to determine when a BSF was formed.

\section{Results}

Tables 1 and 2 provide results for the MAL items from FFSI Aberrant Ideas (a maladaptive variant scale from the openness domain). When five MAL Aberrant Ideas items were included with the 30 FFM facet scores, parallel analysis and Velicer's MAP test recommended a five-factor solution (displayed in Table 1). It is evident from Table 1 that the five MAL Aberrant Ideas items loaded within the FFM domain of openness. When six to nine items were included, parallel analysis recommended six factors. When ten items were included, both number of factors tests recommended six factors. Extraction of six factors and inspection of the factor loadings indicated that a BSF was formed when six items were included in the analysis. Table 2 displays the factor loadings for this analysis, in which six MAL Aberrant Ideas items formed a BSF, separating from FFM openness. Extraction of six factors and examination of the factor loadings when seven, eight, nine, and ten MAL Aberrant Ideas items were included showed that the sixth factor continued to be an Aberrant Ideas BSF.

Tables 3 and 4 provide results for the MAL items from PID-5 Rigid Perfectionism (a maladaptive variant scale from the conscientiousness domain). When only two MAL Rigid Perfectionism items were included, parallel analysis and the MAP test recommended a fivefactor solution, with these items loading in conscientiousness when five factors were extracted (see Table 3). When three to five MAL Rigid Perfectionism items were included, parallel analysis recommended five factors. When six to ten items were included, both 
number of factors tests recommended six factors, with the exception of when nine items were included and the MAP test recommended seven factors. Extraction of six factors and inspection of the factor loadings indicated that a BSF was formed when three items were included in the analysis. Table 4 displays the factor loadings for the analysis in which four MAL Rigid Perfectionism items formed a BSF, separating from FFM conscientiousness. Extraction of six factors and examination of the factor loadings when five, six, seven, eight, nine, and ten MAL Rigid Perfectionism items were included showed that the sixth factor continued to be a Rigid Perfectionism BSF.

Space limitations would clearly prohibit a provision of the factor analyses for all $25 \mathrm{MAL}$ scales (i.e., two tables for each of the 25 scales). Table 5 summarizes the results for the items from all 25 MAL scales. On average, a BSF was formed when 4.2 items (median $=4$ ) were added to the analysis with the 30 FFM facet scales. Provided below is a summary of these results for each domain of the FFM.

\section{Neuroticism}

Bloated specific factors formed for all of the four MAL Neuroticism sets of items. Parallel analysis or the MAP test began recommending the extraction of more than five factors when two to four MAL Neuroticism items were included. BSFs were formed on average with 5.8 items (median $=6.5$ ) were included. When five-factor solutions were recommended by both number of factors tests, factor loadings indicated that the MAL items loaded primarily within the FFM neuroticism domain (but also at times secondarily within FFM openness).

\section{Extraversion}

Bloated specific factors formed for all but one of the four MAL Extraversion sets of items. The one exception occurred for the items within CAT-PD Domineering. For the remaining three MAL Extraversion scales, parallel analysis or the MAP test began recommending the extraction of more than five factors when two to three items were included. BSFs were formed on average when 4.7 items (median $=3$ ) were included. When five-factor solutions were recommended by both number of factors tests, factor loadings indicated that the items from the MAL Extraversion scales loaded together within FFM extraversion and agreeableness factors. Parallel analysis and the MAP did recommend five-factor solutions when one to three CAT-PD Domineering items were included, and a six-factor solution when six items were included, but the six CAT-PD Domineering items did not separate from the FFM domains. The six items instead loaded within the extraversion and agreeableness factors.

\section{Openness}

Bloated specific factors formed for all of the six MAL Openness sets of items. Parallel analysis or the MAP test began recommending the extraction of more than five factors when one to six maladaptive openness items were included in the analysis (see Tables 1 and 2 for the factor loadings for the FFSI Aberrant Ideas items). BSFs were formed on average when 3.8 items (median $=4$ ) were included in the analysis. When five-factor solutions were recommended by both number of factors tests, factor loadings indicated that the items from the MAL Openness scales loaded together within the FFM openness factor. 


\section{Agreeableness}

Bloated specific factors formed for all but one of the seven MAL Agreeableness sets of items. For the remaining six MAL Agreeableness scales, parallel analysis or the MAP test began recommending the extraction of more than five factors when two to six MAL Agreeableness items were included. BSFs were formed on average when 3.2 items (median $=2$ ) were included. When five-factor solutions were recommended by both number of factors tests, factor loadings indicated that the MAL items loaded together within the FFM agreeableness and extraversion factors. The one exception occurred for the FFAvA Timorous items, and the result may have simply reflected (in part) the relatively low number of items in this particular scale (i.e., seven). The FFAvA Timorous items never bound together to form a separate factor; parallel analysis and the MAP test always recommended a five-factor solution.

\section{Conscientiousness}

Bloated specific factors formed for all of the four MAL Conscientiousness sets of items. Parallel analysis or the MAP test began recommending the extraction of more than five factors when three MAL Conscientiousness items were included. Tables 3 and 4 provide the results for the PID-5 Rigid Perfectionism items. BSFs were formed on average when 4.5 items (median $=3.5$ ) were included. When five-factor solutions were recommended by both number of factors tests, factor loadings indicated that the MAL Conscientiousness items loaded together within the FFM conscientiousness factor.

\section{Discussion}

One may question whether alerting to the presence of BSFs is sufficiently novel or informative. Perhaps researchers are actually fully aware of BSFs, carefully avoid their presence, and/or recognize their presence when they do occur. However, we would in fact suggest that there has been relatively little recognition or appreciation of the possible presence of a BSF within the recent personality structure literature. Indeed, we would respectfully suggest two instances of BSFs within FFM-maladaptive trait scale studies that went unnoticed by the authors (and perhaps the reviewers). In both instances, factor analysis was used to suggest that maladaptive aspects of the self (i.e., in one case, schizotypal symptoms, and in the other, selfpathology) fell outside of the FFM personality structure, but we would suggest that both cases represented occurrences of a BSF.

For example, Watson et al. (2008) proposed a structure of personality and personality disorder that included six personality domains, with normal and abnormal variants for four of them (each of which aligned with four of the five domains of the FFM), but no abnormal variant for the fifth domain, openness, and no normal variant for the sixth domain, oddity/ dissociation. This six-domain model of personality and personality disorder was replicated across two factor analyses. In one case, they submitted to the factor analyses the correlations among the NEO-PI-R, the Eysenck Personality Questionnaire (EPQ; Eysenck \& Eysenck, 1975), the Big Five Inventory (Benet-Martinez \& John, 1998), and five scales of oddity/ dissociation. The five scales of oddity/dissociation separated from the FFM with two Schedule for Nonadaptive and Adaptive Personality-2 (SNAP-2; Clark, Simms, Wu, \& 
Casillas, 2014) scales to form their own unique factor. In a second study, they submitted 10 FFM domain scales (two for each domain) along with thirteen scales of oddity and dissociation. Once again, nine oddity scales separated to form their own distinct, sixth factor. Watson et al. (2008) concluded that "the results of these studies establish the existence of an Oddity factor that is ... distinct from Openness and the other Big Five dimensions" (p. 1545).

However, as suggested by Wright (2017), in both factor analyses the traits of oddity and/or dissociation were substantially over-represented relative to the assessment of openness and/or its facets (e.g., 13 scales of oddity and only two scales of openness). The oddity/ dissociation scales were much more highly related to one another than they were with openness, and therefore separated to form their own, homogeneous factor. "In each of their analyses it could be argued that they over-saturated their models with scales related to schizotypy/oddity, which may have served to virtually guarantee that a separate factor would emerged for schizotypy/oddity" (Wright, 2017, p. 232). Similarly, in the current study, items from six alternative measures of schizotypal cognition and/or behavior initially loaded with FFM openness, but then separated to form their own distinct factor when a sufficient number for a BSF were included in the factor analysis.

Berghuis, Kamphuis, and Verheul (2012) postulated that self-pathology is distinct and separate from FFM personality structure. They administered (a) the 19 scales of the General Assessment of Personality Disorders (GAPD) which includes 15 scales of self-identity dysfunction and 4 scales of interpersonal dysfunction (Livesley, 2006), (b) the 16 scales from the Severity Indices for Personality Problems (SIPP-118; Verheul et al., 2008), and (c) the NEO Personality Inventory Revised (NEO PI-R; Costa \& McCrae, 1992). Parallel analysis, used to identify the recommended number of factors to extract from the data (Horn, 1965), recommended a seven-factor solution. Six of the seven factors were well defined by NEO PI-R scales. However, the first factor was defined solely by the 15 GAPD and 4 SIPP-118 self-pathology scales, completely separate from the scales of the FFM. Berghuis et al. (2012) concluded that self-pathology and the FFM were "clearly distinct components of personality" (Berghuis et al., 2012, p. 704). They stated, "Our findings support the distinction between personality traits and personality dysfunction laid down in the recent proposal by the Personality and Personality Disorders Work Group of the DSM-5 Task Force" (Berghuis et al., 2012, p. 704).

Oltmanns and Widiger (2016), however, suggested that the unique self-pathology factor was likely an illustration of a BSF. The GAPD self-pathology scales could be understood as 15 highly correlated indicators of a particular facet of neuroticism. GAPD self-pathology scales include (for instance) poor sense of boundaries (e.g., "I worry that I will lose the sense of who I really am"), fragmentary self-other representations ("I have very contradictory feelings about myself'), defective sense of self ("Sometimes I think that I am seriously flawed in some way"), and poor sense of boundaries (e.g., "I worry that I will lose the sense of who I really am"). If only a smaller subset of GAPD self-pathology scales were included, rather than 15, these scales might in fact load together on a factor with other FFM neuroticism indicators. Oltmanns and Widiger replicated Berghuis et al.'s findings with the 19 scales of the GAPD and 30 FFM facets. Parallel analysis recommended a six-factor 
solution, and the self-pathology scales indeed loaded on a factor that was separate from the FFM. However, when only a subset of three GAPD selfpathology scales were included, parallel analysis recommended a five-factor solution, and the GAPD self-pathology scales loaded together on a factor with other FFM neuroticism indicators, yielding results that suggested that self-pathology does fall within the FFM personality structure.

The current study demonstrated that it is perhaps not particularly difficult to create BSFs to separate items (or scales) from any particular domain of the FFM. Maladaptive items were obtained from the CAT-PD, PID-5, and FFMPD (as well as additional) scales that in theory are expected to load within an adaptive pole of a respective FFM domain. For example, for openness, items were included from the FFSI Aberrant Ideas, FFSI Odd-Eccentric, FFSI Aberrant Perceptions, CAT-PD Peculiarity, CAT-PD Fantasy Proneness, and PID-5 Eccentricity; for agreeableness, items were included from the FFDI Subservience, FFDI Self-Effacing, FFAvA Timorousness, CAT-PD Submissiveness, PID-5 Submissiveness, and IPIP Dependence; and for extraversion items from FFNI Authoritativeness, CAT-PD Domineering, EPA Dominance, and NPI Leadership/Authority. For all of the 25 scales, the respective items initially loaded within the expected domains (albeit extraversion and agreeableness items often loaded on both factors), consistent with the expected bipolarity of maladaptive personality structure (Samuel, 2011; Widiger et al., 2017). However, items from 23 out of 25 maladaptive personality trait scales though emerged as BSFs when enough items were included, appearing now as separate higher-order constructs. To the investigator submitting a set of homogeneous items or closely related maladaptive trait scales to a factor analysis, the items or scales could very well define their own unique, seemingly higher-order construct, separate from the domains of the FFM. We suggest that this went unrecognized in two prior FFM personality studies (e.g., Berghuis et al., 2012; Watson et al., 2008) and will likely occur again.

In the current study, there were two (of 25 possible) instances wherein a BSF did not form. In both cases, for the FFAvA Timorous and CAT-PD Domineering items, there was a relatively lower number of items as compared to the other MAL scales. If additional items had been available, perhaps a BSF might have formed. The results for CAT-PD Domineering may have also reflected the fact that its items were anchored within two factors, the domains of antagonism and extraversion.

There was a degree of cross-loading of items across FFM domains in the present investigation, particularly for items from extraversion and agreeableness. Cross-loading for extraversion and agreeableness though is a common finding at the scale level (e.g., Crego et al., 2018; Oltmanns \& Widiger, 2016), consistent with the continuous distribution of interpersonal traits around respective locations of the interpersonal circumplex (Pincus \& Hopwood, 2012). While a factor solution with perfect simple structure would be preferable (i.e., only the facets from a given domain loading on each factor), facet cross-loading is generally not surprising amongst the FFM indicators given the intercorrelated nature of the domains (Hopwood \& Donnellan, 2010).

It is also useful to note that there are other means of exploring maladaptive variants of traditionally adaptive FFM poles. The approach considered in the current study was via 
factor analysis. However, another approach that has received considerable attention is through the exploration of curvilinear relationships (e.g., Carter, Miller, \& Widiger, in press; Nickels, Chernyshenko, \& Roberts, in press; Samuel \& Tay, in press). Maladaptive bipolarity may be found in relationships between personality traits and life outcomes through the obtainment of curvilinear relationships with functioning. For example, elevations on conscientiousness facets typically suggest improved productivity and performance, yet a curvilinear relationship with productivity can also be obtained, suggesting a perfectionism that may impair occupational functioning (Carter et al., in press). Likewise, elevated scores on agreeableness and extraversion will typically suggest satisfaction and social effectiveness, but curvilinear relationships can also occur, suggesting a submissiveness and risk taking or social dominance at the highest levels that may impair social connections.

The present findings were meant to generalize to the population of adults in the United States who have been in mental health treatment. We expect that it will generalize to this population and likely to community adults in the United States as well. We have no reason to believe that the results depend on other characteristics of the participants, materials, or context.

\section{Recognizing BSFs in Factor Analytic Research}

This bears the question of how investigators may recognize BSFs. Whether or not a BSF will form will not always be readily apparent, as it depends on the number of the potential BSF indicators and the strength of their associations with one another relative to the number and strength of the other respective facet scales (Cattell \& Tsujioka, 1964; Wright, 2017). For example, the MAL Aberrant Ideas items correlated more highly with one another $(r=.49)$ relative to the average correlation among the other openness facets $(\mathrm{r}=.24)$. One can also consider the content. A BSF is suggested when the content of the new (BSF) factor (e.g., aberrant ideas) is narrower and more homogenous than the other domain level factors (e.g., openness to ideas, fantasy, and actions) and, perhaps even more telling, if the new factor can be understood as a component of the broader factor (e.g., aberrant ideas as a variant of openness to ideas).

\section{Limitations}

We used items from multiple maladaptive variant scales of the FFM domains to form BSFs in the present study, rather than scales. This study would not have been possible using scales because of the large number of scales it would likely have taken to demonstrate BSFs for all five domains. The decision to use items instead of scales reduced the overall number of items participants had to complete by roughly eight or nine times. However, because items are less reliable than scales, the intercorrelations, or binding, of the MAL items to each other was likely lower than what would have been found using scales, perhaps making the demonstration of a BSF more difficult. Indeed, in Oltmanns and Widiger (2016), the median intercorrelations for the BSF scales in several separate studies were greater than $r=.70$, higher than the intercorrelations for the MAL items used in the present study (median M scale MIC in the present study was $r=.49$ ). 
Another potential limitation was the number of participants that were dropped from the dataset for not completing $80 \%$ of every given measure $(n=117)$. It is more common for participants to quit early in an online crowdsourced study environment such as MTurk than in a traditional assessment environment (i.e., perhaps because of no ramifications or social pressures associated with dropping out of an online study). Further, 38 participants were excluded due to non-content-based responding. The dropout rate $(22 \%)$ is similar to what has been found previously in other MTurk studies (Zhou \& Fishbach, 2016); however, future studies should consider ways to limit attrition from online data collection platforms (c.f., Zhou \& Fishbach, 2016).

\section{Conclusion}

The structure of personality is one of the most popular topics in personality research. Factor analysis is one of the primary methodological tools used by researchers to examine this question. Factor analysis, though, is susceptible to imperfections, one of which is that the results are sensitive to the number and content of the scales submitted (Cattell, 1978; Haynes, Smith, \& Hunsley, 2011; Wright, 2017). The present findings demonstrate that when several homogeneous personality indicators are submitted to an analysis with other FFM facets, they can emerge as a higher order domain, when they are in fact best understood as a lower order component. The results of the current study emphasize the importance of considering the relative representation of the components or facets of a respective domain when exploring the structure of personality.

\section{Acknowledgments}

This research was supported by the National Institute of Aging under Award Number F31AG055233. The content is solely the responsibility of the authors and does not necessarily represent the official views of the National Institutes of Health.

\section{References}

American Psychiatric Association (2013). Diagnostic and statistical manual of mental disorders (5th ed.). Washington, DC: American Psychiatric Association.

Bagby RM, \& Widiger TA (2018). Five factor model personality disorder scales: An introduction to a special section on assessment of maladaptive variants of the five-factor model. Psychological Assessment, 30, 1-9. [PubMed: 29323509]

Benet-Martinez V, \& John OP (1998). Los Cinco Grandes across cultures and ethnic groups: Multitrait-multimethod analyses of the Big Five in Spanish and English. Journal of Personality and Social Psychology, 75, 729-750. [PubMed: 9781409]

Berghuis H, Kamphuis JH, \& Verheul R (2012). Core features of personality disorder: Differentiating general personality dysfunctioning from personality traits. Journal of Personality Disorders, 26, 704-716. [PubMed: 23013339]

Buhrmester MD, Talaifar S, \& Gosling SD (2018). An evaluation of Amazon's Mechanical Turk, its rapid rise, and its effective use. Perspectives on Psychological Science, 13, 149-154. [PubMed: 29928846]

Carter NT, Miller JD, \& Widiger TA (in press). Extreme personalities at work and in life Current Directions in Psychological Science.

Cattell RB (1978). The scientific use of factor analysis in behavioral and life sciences. New York, NY: Plenum Press. 
Cattell RB, \& Tsujioka B (1964). The importance of factor-trueness and validity, versus homogeneity and orthogonality, in test scales. Educational and Psychological Measurement, 1, 3-30.

Chandler J, \& Shapiro D (2016). Conducting clinical research using crowdsourced convenience samples. Annual Review of Clinical Psychology, 12, 53-81.

Clark LA, Simms LJ, Wu K,D, \& Casillas A (2014). Schedule for Nonadaptive and Adaptive Personality-2nd Edition (SNAP-2): Manual for administration, scoring, and interpretation. Notre Dame, IN: University of Notre Dame.

Crego C, Oltmanns JR, \& Widiger TA (2018). FFMPD Scales: Comparisons to the FFM, PID-5, and CAT-PD-SF. Psychological Assessment, 30, 62-73. [PubMed: 29323514]

Dinno A (2012). paran: Horn's Test of Principal Components/Factors. R package version 1.5.1. http:// CRAN.R-project.org/package $=$ paran

Edmundson M, Lynam DR, Miller JD, Gore WL, \& Widiger TA (2011). A five-factor measure of schizotypal personality traits. Assessment, 18, 321-334. [PubMed: 21571737]

Enders CK (2006). A primer on the use of modern missing-data methods in psychosomatic medicine research. Psychosomatic Medicine, 68, 427-436. [PubMed: 16738075]

Eysenck HJ, \& Eysenck SBG (1975). Manual of the Eysenck Personality Questionnaire (junior and adult). London, England: Hodder and Stoughton.

Glover N, Miller JD, Lynam DR, Crego C, \& Widiger TA (2012). The five-factor narcissism inventory: A five-factor measure of narcissistic personality traits. Journal of Personality Assessment, 94, 500-512. [PubMed: 22475323]

Goldberg LR, Johnson JA, Eber HW, Hogan R, Ashton MC, Cloninger CR, \& Gough HC (2006). The International Personality Item Pool and the future of public-domain personality measures. Journal of Research in Personality, 40, 84-96.

Gore WL, Presnail JR, Miller JD, Lynam DR, \& Widiger TA (2012). A five-factor measure of dependent personality traits. Journal of Personality Assessment, 94, 488-499. [PubMed: 22475264]

Green SB, Levy R, Thompson MS, Lu M, \& Lo WJ (2012). A proposed solution to the problem with using completely random data to assess the number of factors with parallel analysis. Educational and Psychological Measurement, 72, 357-374.

Haynes SN, Smith GT, \& Hunsley JD (2011). Scientific foundations of clinical assessment. New York: Routledge.

Hayton JC, Allen DG, \& Scarpello V (2004). Factor retention decisions in exploratory factor analysis: A tutorial on parallel analysis. Organizational Research Methods, 7, 191-205.

Hopwood CJ, \& Donnellan MB (2010). How should the internal structure of personality inventories be evaluated? Personality and Social Psychology Review, 14, 332-346. [PubMed: 20435808]

Horn JL (1965). A rationale and test for the number of factors in factor analysis. Psychometrika, 30, 179-185. [PubMed: 14306381]

John OP, Naumann LP, \& Soto CJ (2008). Paradigm shift to the integrative big five trait taxonomy. Handbook of personality: Theory and research, 3, 114-158.

Krueger RF, Derringer J, Markon KF, Watson D, \& Skodol AE (2012). Initial construction of a maladaptive personality trait model and inventory for DSM-5. Psychological Medicine, 42, 18791890. [PubMed: 22153017]

Krueger RF, Eaton NR, Derringer J, Markon KE, Watson D, \& Skodol AE (2011). Personality in DSM-5: Helping delineate personality disorder content and framing the meta-structure. Journal of Personality Assessment, 93, 325-331. [PubMed: 22804671]

Livesley WJ (2006). General assessment of personality disorder (GAPD). Department of Psychiatry, University of British Columbia.

Lykken DT (1971). Multiple factor analysis and personality research. Journal of Experimental Research in Personality, 5, 161-170.

Lynam DR, Gaughan ET, Miller JD, Miller DJ, Mullins-Sweatt S, \& Widiger TA (2011). Assessing the basic traits associated with psychopathy: Development and validation of the Elemental Psychopathy Assessment. Psychological Assessment, 23, 108-124. [PubMed: 21171784] 
Lynam DR, Loehr A, Miller JD, \& Widiger TA (2012). A five-factor measure of avoidant personality: The FFAvA. Journal of Personality Assessment, 94, 466-474. [PubMed: 22519846]

Maples JL, Guan L, Carter NT, \& Miller JD (2014). A test of the International Personality Item Pool representation of the Revised NEO Personality Inventory and development of a 120-item IPIPbased measure of the five factor model. Psychological Assessment, 26, 1070-1084. [PubMed: 24932643]

Miller JD, Crowe M, Weiss B, Maples-Keller JL, \& Lynam DR (2017). Using online, crowdsourcing platforms for data collection in personality disorder research: The example of Amazon's Mechanical Turk. Personality Disorders: Theory, Research, and Treatment, 8, 26-34.

Mulder RT, Horwood J, Tyrer P, Carter J, \& Joyce PR (2016). Validating the proposed ICD-11 domains. Personality and Mental Health, 10, 84-95. [PubMed: 27120419]

Mullins-Sweatt SN, Jamerson JE, Samuel SB, Olson DR, \& Widiger TA (2006). Psychometric properties of an abbreviated instrument for the assessment of the five factor model. Assessment, 13, 119-137. [PubMed: 16672728]

Nickel LB, Roberts BW, \& Chernyshenko OS (in press). No evidence of a curvilinear relation between conscientiousness and relationship, work, and health outcomes. Journal of Personality and Social Psychology.

O'Connor BP (2000). SPSS and SAS programs for determining the number of components using parallel analysis and Velicer's MAP test. Behavior research methods, instruments, \& computers, 32(3), 396-402.

O'Connor B (2017). paramap: Factor analysis functions for assessing dimensionality. R package version 1.3. Retrieved from https://people.ok.ubc.ca/brioconn/nfactors/paramap.pdf

Oltmanns JR, \& Widiger TA (in press). Assessment of fluctuation between grandiose and vulnerable narcissism: Development and initial validation of the FLUX scales. Psychological Assessment, doi: $10.1037 /$ pas0000616

Oltmanns JR, \& Widiger TA (2016). Self-pathology, the five factor model, and bloated specific factors: A cautionary tale. Journal of Abnormal Psychology, 125, 423-434. [PubMed: 26845254]

Patrick CJ, Fowles DC, \& Krueger RF (2009). Triarchic conceptualization of psychopathy: Developmental origins of disinhibition, boldness, and meanness. Development and Psychopathology, 21, 913-938. [PubMed: 19583890]

Pincus AL, \& Hopwood CJ (2012). A contemporary interpersonal model of personality pathology and personality disorder In Widiger TA (Ed.), The Oxford handbook of personality disorders (pp. 372398). New York: Oxford University Press.

R Core Team (2013). R: A language and environment for statistical computing Vienna, Austria: R Foundation for Statistical Computing. <http://www.R-project.org/>.

Raskin R, \& Terry H (1988). A principal-components analysis of the Narcissistic Personality Inventory and further evidence of its construct validity. Journal of Personality and Social Psychology, 54, 890. [PubMed: 3379585]

Revelle W (2017). Psych: Procedures for psychological, psychometric, and personality research. R package version 1.7.5. Retrieved from https://cran.r-project.org/web/packages/psych/psych.pdf

Rojas SR, \& Widiger TA (2014). Convergent and discriminant validity of the Five Factor Form. Assessment, 2, 143-157.

Rojas SL, \& Widiger TA (2018). Convergent and discriminant validity of the Five Factor Form and the Sliderbar Inventory. Assessment, 5, 222-234.

Samuel DB (2011). Assessing personality in the DSM-5: The utility of bipolar constructs. Journal of Personality Assessment, 93, 390-397. [PubMed: 22804678]

Samuel DB, Mullins-Sweatt SN, \& Widiger TA (2013). An investigation of the factor structure and convergent and discriminant validity of the Five-Factor Model Rating Form. Assessment, 20, 24 35. [PubMed: 22871990]

Samuel DB, Riddell ADB, Lynam DR, Miller JD, \& Widiger TA (2012). A five-factor measure of obsessive-compulsive personality traits. Journal of Personality Assessment, 94, 456-465.

[PubMed: 22519829]

J Res Pers. Author manuscript; available in PMC 2019 October 01. 
Samuel DB, \& Tay L (in press). Aristotle's golden mean and the importance of bipolarity for personality models: A commentary on "Personality traits and maladaptivity: Unipolarity versus bipolarity". Journal of Personality.

Simms LJ, Goldberg LR, Roberts JE, Watson D, Welte J, \& Rotterman JH (2011). Computerized adaptive assessment of personality disorder: Introducing the CAT-PD project. Journal of Personality Assessment, 93, 380-389. [PubMed: 22804677]

Trull TJ (2012). The five-factor model of personality disorder and DSM-5. Journal of Personality, 80, 1697-1720. [PubMed: 22321203]

Tyrer P, Reed GM \& Crawford MJ (2015). Classification, assessment, prevalence, and effect of personality disorder. Lancet, 385, 717-726. [PubMed: 25706217]

Velicer WF, Eaton CA, \& Fava JL (2000). Construct explication through factor or component analysis: A review and evaluation of alternative procedures for determining the number of factors or components In Goffin RD, \& Helmes E (Eds.), Problems and solutions in human assessment: Honoring Douglas N. Jackson at seventy (pp. 41-71). Boston: Kluwer.

Verheul R, Andrea H, Berghout CC, Dolan C, Busschbach JJ, van der Kroft PJ, .. \& Fonagy P (2008). Severity Indices of Personality Problems (SIPP-118): Development, factor structure, reliability, and validity. Psychological Assessment, 20, 23-34. [PubMed: 18315396]

Watson D, Clark LA, \& Chmielewski M (2008). Structures of personality and their relevance to psychopathology: II. Further articulation of a comprehensive unified trait

Widiger TA, \& Crego C (in press). The bipolarity of normal and abnormal personality structure; Implications for assessment. Psychological Assessment.

Widiger TA, Gore WL, Crego C, Rojas SL, \& Oltmanns JR (2017). Five factor model and personality disorder In Widiger TA (Ed.), The Oxford handbook of the five factor model (pp. 449-478). NY: Oxford University Press.

Widiger TA, \& Trull TJ (2007). Plate tectonics in the classification of personality disorder: shifting to a dimensional model. American Psychologist, 62, 71-83. [PubMed: 17324033]

Williams TF, \& Simms LJ (in press). Personality traits and maladaptivity: unipolarity vs. bipolarity. Journal of Personality.

Wright AGC (2017). Factor analytic support for the five-factor model In Widiger TA (Ed.) The Oxford handbook of the five factor model. New York, NY: Oxford University Press.

Wright AGC, \& Simms LJ (2014). On the structure of personality disorder traits: Conjoint analysis of the CAT-PD, PID-5, and NEO PI-3 trait models. Personality Disorders: Theory, Research, and Treatment, 5, 43-54.

Zhou H, \& Fishbach A (2016). The pitfall of experimenting on the web: How unattended selective attrition leads to surprising (yet false) research conclusions. Journal of Personality and Social Psychology, 111, 493-504. [PubMed: 27295328]

J Res Pers. Author manuscript; available in PMC 2019 October 01. 


\section{Highlights}

- It is hypothesized that there are maladaptive traits at each pole of the FFM.

- $\quad$ Bloated specific factors (BSFs) though can complicate this research.

- Maladaptive items from 25 scales were factor analyzed with the 30 facets of the FFM.

- The maladaptive items loaded on the adaptive poles of the FFM

- But, in 23 of 25 cases, BSFs were eventually formed. 
Table 1.

Five FFSI-Aberrant Ideas Items Loading with FFM Openness.

\begin{tabular}{|c|c|c|c|c|c|c|}
\hline & \multicolumn{6}{|c|}{ Factor } \\
\hline & 1 & 2 & 3 & 4 & 5 & h2 \\
\hline $\mathrm{C} 4$ & .89 & .06 & -.02 & .04 & .03 & .76 \\
\hline $\mathrm{C} 1$ & .83 & .00 & .01 & .04 & .09 & .72 \\
\hline $\mathrm{C} 5$ & .73 & -.18 & .16 & -.13 & -.04 & .70 \\
\hline E4 & .61 & -.15 & -.17 & .00 & .11 & .56 \\
\hline $\mathrm{C} 2$ & .55 & .06 & .23 & -.09 & -.13 & .33 \\
\hline E3 & .54 & -.17 & -.45 & .11 & -.01 & .65 \\
\hline $\mathrm{C} 3$ & .53 & .07 & .48 & -.03 & .25 & .61 \\
\hline $\mathrm{N} 1$ & .01 & .88 & -.02 & .03 & .06 & .76 \\
\hline $\mathrm{N} 2$ & .14 & .69 & -.40 & .03 & -.12 & .54 \\
\hline N3 & -.22 & .69 & -.01 & .07 & -.06 & .68 \\
\hline N6 & -.35 & .65 & .04 & -.02 & .08 & .71 \\
\hline N4 & -.34 & .59 & .21 & .03 & .07 & .71 \\
\hline $\mathrm{O} 3$ & .12 & .55 & .01 & .10 & .41 & .40 \\
\hline $\mathrm{O} 4$ & -.13 & -.51 & -.16 & .38 & .21 & .45 \\
\hline C6 & .27 & -.15 & .69 & -.03 & -.07 & .54 \\
\hline A4 & -.15 & -.18 & .64 & -.07 & .39 & .65 \\
\hline E5 & .12 & -.20 & -.60 & .22 & .21 & .59 \\
\hline A2 & .13 & .06 & .57 & -.10 & .25 & .47 \\
\hline A5 & -.31 & .31 & .52 & -.04 & .15 & .62 \\
\hline E2 & .02 & -.33 & -.46 & -.17 & .43 & .59 \\
\hline N5 & -.32 & .27 & -.46 & .18 & .12 & .45 \\
\hline FFSI_I188 & .05 & -.02 & -.03 & .67 & -.02 & .45 \\
\hline FFSI_I179 & -.05 & .05 & -.08 & .65 & -.20 & .50 \\
\hline FFSI_I197 & -.03 & .05 & -.10 & .62 & -.09 & .44 \\
\hline FFSI_I98 & .05 & .09 & -.16 & .62 & -.14 & .48 \\
\hline O5 & .10 & -.19 & .25 & .61 & .19 & .46 \\
\hline $\mathrm{O} 1$ & -.13 & .03 & -.05 & .61 & .08 & .41 \\
\hline $\mathrm{O} 2$ & .12 & -.02 & .30 & .52 & .24 & .41 \\
\hline FFSI_I170r & -.11 & .08 & .00 & .42 & -.20 & .26 \\
\hline O6 & -.17 & .00 & .13 & .33 & .06 & .15 \\
\hline A6 & -.05 & .23 & .19 & .07 & .81 & .74 \\
\hline A3 & .10 & .09 & .17 & .01 & .78 & .69 \\
\hline E1 & .19 & -.19 & -.33 & -.09 & .68 & .75 \\
\hline A1 & -.10 & -.21 & -.15 & -.27 & .54 & .43 \\
\hline E6 & .24 & -.33 & -.25 & .03 & .48 & .62 \\
\hline
\end{tabular}

Note. $\mathrm{E}=$ extraversion, $\mathrm{A}=$ agreeableness, $\mathrm{C}=$ conscientiousness, $\mathrm{N}=$ neuroticism, $\mathrm{O}=$ openness, FFNI_I $=$ Five-Factor Schizotypal Inventory Aberrant Ideas item.

J Res Pers. Author manuscript; available in PMC 2019 October 01. 
Table 2.

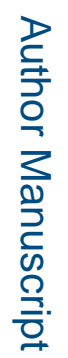

Bloated Specific FFSI Aberrant Ideas Factor

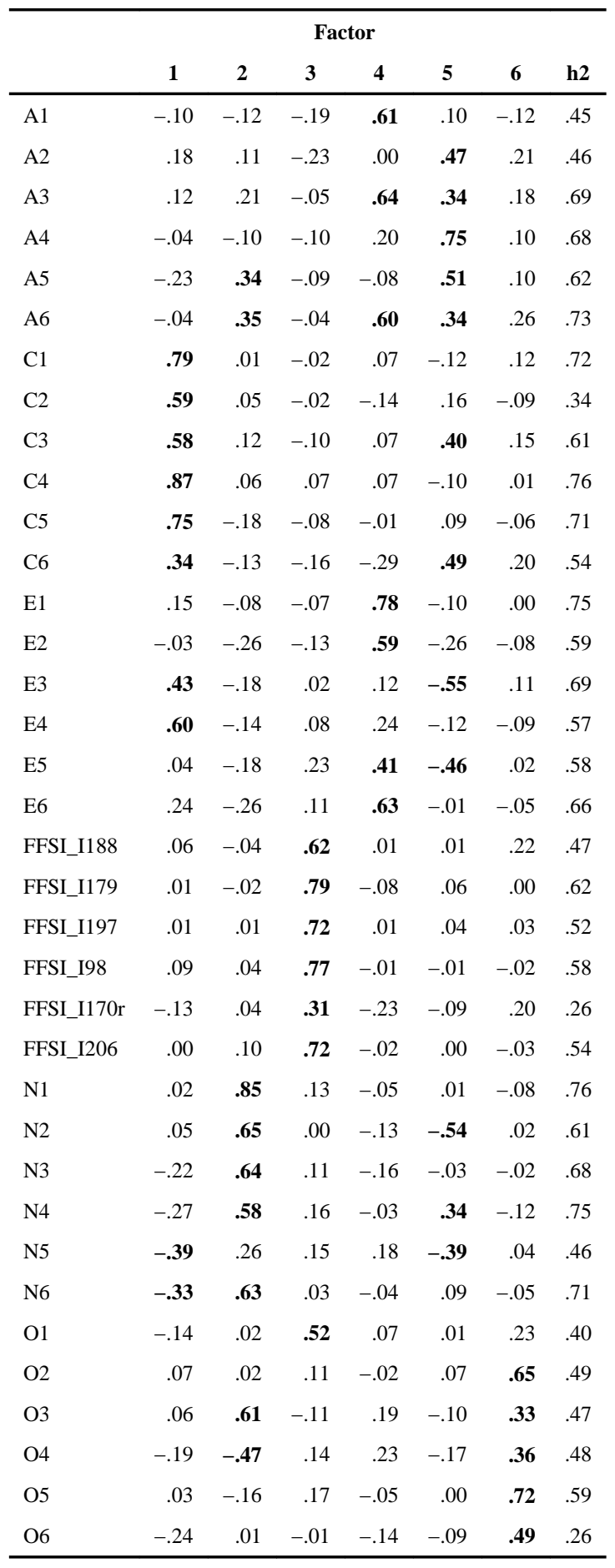

Note. $\mathrm{E}=$ extraversion, $\mathrm{A}=$ agreeableness, $\mathrm{C}=$ conscientiousness, $\mathrm{N}=$ neuroticism, $\mathrm{O}=$ openness, FFSI_I = Five-Factor Schizotypal Inventory, Aberrant Ideas item.

J Res Pers. Author manuscript; available in PMC 2019 October 01. 
Table 3.

Two PID-5 Rigid Perfectionism Items Loading with FFM C.

\begin{tabular}{|c|c|c|c|c|c|c|}
\hline & \multicolumn{6}{|c|}{ Factor } \\
\hline & 1 & 2 & 3 & 4 & 5 & h2 \\
\hline N1 & .88 & .10 & -.04 & -.01 & -.03 & .73 \\
\hline N6 & .75 & -.22 & .02 & -.02 & -.07 & .71 \\
\hline N3 & .72 & -.11 & -.08 & -.17 & .01 & .67 \\
\hline N4 & .71 & -.21 & .18 & -.05 & -.04 & .71 \\
\hline $\mathrm{N} 2$ & .60 & .20 & -.44 & -.11 & -.01 & .52 \\
\hline $\mathrm{O} 3$ & .57 & .10 & .00 & .29 & .22 & .39 \\
\hline $\mathrm{O} 4$ & -.44 & -.24 & -.27 & .14 & .41 & .49 \\
\hline PID_R140 & .30 & .76 & -.13 & -.12 & -.02 & .56 \\
\hline $\mathrm{C} 4$ & -.15 & .74 & .03 & .15 & .08 & .71 \\
\hline PID_R220 & .23 & .67 & -.07 & -.23 & -.02 & .47 \\
\hline $\mathrm{C} 1$ & -.20 & .67 & .05 & .17 & .14 & .67 \\
\hline $\mathrm{C} 2$ & -.02 & .60 & .28 & -.06 & -.10 & .43 \\
\hline $\mathrm{C} 5$ & -.39 & .57 & .26 & .10 & -.06 & .68 \\
\hline E4 & -.28 & .51 & -.10 & .25 & .02 & .55 \\
\hline E3 & -.31 & .45 & -.45 & .12 & .10 & .66 \\
\hline A4 & -.04 & -.17 & .70 & .26 & .08 & .62 \\
\hline C6 & -.21 & .19 & .68 & -.16 & .12 & .54 \\
\hline $\mathrm{A} 2$ & .06 & .06 & .63 & .15 & .07 & .46 \\
\hline E5 & -.18 & .09 & -.62 & .29 & .14 & .58 \\
\hline $\mathrm{C} 3$ & -.02 & .41 & .55 & .22 & .11 & .60 \\
\hline N5 & .37 & -.23 & -.54 & .08 & .10 & .47 \\
\hline A5 & .42 & -.25 & .51 & -.02 & .04 & .62 \\
\hline E1 & -.14 & .10 & -.17 & .81 & -.03 & .76 \\
\hline A3 & .22 & .05 & .28 & .72 & .14 & .69 \\
\hline A6 & .40 & -.07 & .26 & .68 & .21 & .74 \\
\hline A1 & -.14 & -.16 & .03 & .63 & -.18 & .44 \\
\hline E6 & -.29 & .16 & -.15 & .59 & .03 & .63 \\
\hline E2 & -.30 & -.04 & -.31 & .58 & -.13 & .58 \\
\hline O5 & -.11 & .03 & .01 & -.09 & .80 & .63 \\
\hline $\mathrm{O} 2$ & .06 & .08 & .10 & -.03 & .70 & .52 \\
\hline O1 & .16 & -.10 & -.26 & -.08 & .47 & .30 \\
\hline O6 & .08 & -.17 & -.03 & -.15 & .43 & .22 \\
\hline
\end{tabular}

Note. $\mathrm{E}=$ extraversion, $\mathrm{A}=$ agreeableness, $\mathrm{C}=$ conscientiousness, $\mathrm{N}=$ neuroticism, $\mathrm{O}=$ openness, PID_R = PID-5 Rigid Perfectionism.

J Res Pers. Author manuscript; available in PMC 2019 October 01. 
Table 4.

Bloated Specific PID-5 Rigid Perfectionism Factor

\begin{tabular}{|c|c|c|c|c|c|c|c|}
\hline & \multicolumn{7}{|c|}{ Factor } \\
\hline & 1 & 2 & 3 & 4 & 5 & 6 & h2 \\
\hline N1 & .80 & -.08 & .13 & -.03 & .05 & -.05 & .72 \\
\hline $\mathrm{N} 2$ & .68 & -.14 & .08 & -.05 & -.49 & -.06 & .62 \\
\hline N3 & .67 & -.23 & .00 & -.15 & .04 & -.02 & .68 \\
\hline N6 & .65 & -.08 & -.01 & -.22 & .25 & -.08 & .71 \\
\hline $\mathrm{O} 3$ & .65 & .19 & -.08 & .18 & -.10 & .19 & .45 \\
\hline $\mathrm{N} 4$ & .55 & -.10 & .09 & -.22 & .46 & -.04 & .75 \\
\hline E1 & -.05 & .83 & -.01 & .04 & -.11 & -.02 & .76 \\
\hline E6 & -.27 & .67 & .13 & -.03 & -.03 & .06 & .66 \\
\hline A1 & -.11 & .65 & -.10 & -.06 & .18 & -.17 & .44 \\
\hline E2 & -.22 & .65 & -.05 & -.15 & -.18 & -.11 & .57 \\
\hline $\mathrm{A} 3$ & .26 & .64 & -.06 & .26 & .24 & .15 & .69 \\
\hline A6 & .42 & .59 & -.10 & .15 & .30 & .21 & .73 \\
\hline E5 & -.14 & .41 & .11 &.- .33 & -.41 & .16 & .58 \\
\hline E4 & -.26 & .32 & .31 & .21 & -.20 & .04 & .55 \\
\hline PID_R135 & .12 & .02 & .79 & -.07 & .08 & .05 & .59 \\
\hline PID_R140 & .15 & -.03 & .78 & .08 & -.05 & .00 & .67 \\
\hline PID_R123 & -.06 & .03 & .76 & -.15 & .00 & -.02 & .57 \\
\hline PID_R220 & .06 & -.14 & .71 & .05 & .01 & .00 & .55 \\
\hline $\mathrm{C} 2$ & -.14 & -.03 & .52 & .34 & .16 & -.08 & .47 \\
\hline $\mathrm{C} 3$ & .07 & .12 & .04 & .72 & .11 & .10 & .64 \\
\hline A2 & .13 & .01 & -.18 & .57 & .27 & .05 & .50 \\
\hline $\mathrm{C} 1$ & -.08 & .16 & .24 & .56 & -.35 & .14 & .71 \\
\hline C5 & -.33 & .11 & .23 & .56 & -.11 & -.05 & .68 \\
\hline C6 & -.21 & -.24 & .02 & .55 & .33 & .12 & .53 \\
\hline N5 & .36 & .12 & -.03 & -.51 & -.21 & .09 & .47 \\
\hline $\mathrm{C} 4$ & -.09 & .17 & .37 & .50 & -.29 & .09 & .72 \\
\hline A4 & -.14 & .20 & -.05 & .21 & .74 & .11 & .70 \\
\hline E3 & -.18 & .20 & .18 & .12 & -.62 & .10 & .69 \\
\hline A5 & .36 & -.13 & -.13 & .11 & .52 & .03 & .61 \\
\hline $\mathrm{O} 1$ & .05 & -.03 & .17 & -.44 & .08 & .52 & .40 \\
\hline $\mathrm{O} 2$ & .05 & -.05 & .04 & .07 & .07 & .71 & .52 \\
\hline O5 & -.09 & -.10 & .00 & .01 & -.02 & .81 & .63 \\
\hline O6 & .13 & -.19 & -.20 & -.04 & -.07 & .42 & .23 \\
\hline $\mathrm{O} 4$ & -.34 & .18 & -.23 & -.20 & -.21 & .41 & .48 \\
\hline
\end{tabular}

Note. $\mathrm{E}=$ extraversion, $\mathrm{A}=$ agreeableness, $\mathrm{C}=$ conscientiousness, $\mathrm{N}=$ neuroticism, $\mathrm{O}=$ openness, $\mathrm{PID} \_\mathrm{R}=\mathrm{PID}-5$ Rigid Perfectionism.

J Res Pers. Author manuscript; available in PMC 2019 October 01. 
Table 5

Number of Factors Recommended by Parallel Analysis and Velicer's MAP Test

\begin{tabular}{|c|c|c|c|c|c|c|c|c|c|c|c|}
\hline \multirow[b]{2}{*}{ Scale } & \multicolumn{10}{|c|}{ Items } & \multirow{2}{*}{$\begin{array}{l}\text { BSF } \\
\text { Items }\end{array}$} \\
\hline & 1 & 2 & 3 & 4 & 5 & 6 & 7 & 8 & 9 & 10 & \\
\hline \multicolumn{12}{|l|}{ Low Neuroticism } \\
\hline EPA Self-Assurance & 5 & 5,6 & 5,6 & 5,6 & 5,6 & 5,6 & 5,6 & 5,7 & 5,7 & - & 6 \\
\hline FFNI Indifference & 5 & 5,6 & 5,6 & 5,6 & 6 & 6 & 6 & 6 & 6 & 6 & 4 \\
\hline EPA Invulnerability & 5 & 5 & 5,6 & 5,6 & 5,6 & 6 & 6 & 6 & 6 & - & 7 \\
\hline TPM Boldness & 5 & 5 & 5 & 5 & 5,7 & 5,7 & 5,7 & 5,7 & 5,7 & 5,7 & 5 \\
\hline \multicolumn{12}{|l|}{ High Extraversion } \\
\hline FFNI Authoritativeness & 5 & 5,6 & 5,6 & 6 & 6 & 6 & 6 & 6 & 6 & 6 & 3 \\
\hline EPA Dominance & 5 & 5 & 5,6 & 5,6 & 6 & 6,7 & 6,7 & 6,7 & 6,7 & - & 9 \\
\hline CAT-PD Domineering & 5 & 5 & 5 & 5,6 & 5,6 & 6 & - & - & - & - & - \\
\hline NPI Leadership/Authority & 5 & 5,6 & 5,6 & 6 & 6 & 6 & 6 & 6 & 6 & - & 2 \\
\hline \multicolumn{12}{|l|}{ High Openness } \\
\hline FFSI Aberrant Ideas & 5 & 5 & 5 & 5 & 5 & 6,5 & 6,5 & 6,5 & 6,5 & 6 & 6 \\
\hline CAT-PD Peculiarity & 5 & 5 & 5 & 6 & 6 & - & - & - & - & - & 4 \\
\hline FFSI Odd-Eccentric & 5 & 5 & 5 & 6,5 & 6 & 6 & 6 & 6 & 6 & 6 & 4 \\
\hline PID-5 Eccentricity & 5 & 5 & 5 & 6,5 & 6 & 6 & 6 & 6 & 6 & 6 & 4 \\
\hline FFSI Aberrant Perceptions & 5 & 5 & 6,5 & 6 & 6 & 6,7 & 6,7 & 6,7 & 6,7 & 6,7 & 3 \\
\hline CAT-PD Fantasy Proneness & 5,6 & 6 & 6 & 6 & 6 & 6 & - & - & - & - & 2 \\
\hline \multicolumn{12}{|l|}{ High Agreeableness } \\
\hline FFDI Subservience & 5 & 5,6 & 5,6 & 6 & 6 & 6 & 6 & 6 & 6 & 6 & 2 \\
\hline FFAvA Timorous & 5 & 5 & 5 & 5 & 5 & 5 & 5 & - & - & - & - \\
\hline FFDI Self-Effacing & 5 & 5,6 & 5,6 & 5 & 5 & 5,6 & 6 & 6 & 6 & 6,7 & 2 \\
\hline CAT-PD Submissiveness & 5 & 5,6 & 6 & 6 & 6 & 6 & - & - & - & - & 2 \\
\hline PID-5 Submissiveness & 5 & 5,6 & 6 & 6 & - & - & - & - & - & - & 2 \\
\hline IPIP RD4 Dependence & 5 & 5 & 5 & 5 & 5 & 6 & 6 & 6 & 6 & 6 & 6 \\
\hline IPIP HEXACO Modesty & 5 & 5 & 5 & 5 & 6 & 6 & 6,7 & 6 & 7 & 7,8 & 5 \\
\hline \multicolumn{12}{|l|}{ High Conscientiousness } \\
\hline FFNI Acclaim-Seeking & 5 & 5 & 5,6 & 5,6 & 5,6 & 5,6 & 5,6 & 5,6 & 5,6 & 5,6 & 3 \\
\hline FFOCI Workaholism & 5 & 5 & 5,6 & 5,6 & 5,6 & 5,6 & 5,6 & 5,6 & 5,6 & 5,6 & 8 \\
\hline CAT-PD Workaholism & 5 & 5 & 5,6 & 6 & 6 & 6 & - & - & - & - & 4 \\
\hline PID-5 Rigid Perfectionism & 5 & 5 & 5,6 & 5,6 & 5,6 & 6 & 6 & 6 & 6,7 & 6 & 3 \\
\hline
\end{tabular}

Note. The first number indicates the recommended number of factors to extract by parallel analysis and the second number indicates the recommended number of factors to extract by the MAP test. BSF = bloated specific factor, FFNI $=$ Five-Factor Narcissism Inventory, EPA = Elemental Psychopathy Assessment, NPI = Narcissistic Personality Inventory, CAT-PD = Computerized-Adaptive Test for Personality Disorders Static Form, FFDI = Five-Factor Dependent Inventory, FFAvA = Five-Factor Avoidant Inventory, PID-5 = Personality Inventory for DSM-5, IPIP = International Personality Item Pool, FFOCI = Five-Factor Obsessive-Compulsive Inventory, TPM = Triarchic Model of Psychopathy.

J Res Pers. Author manuscript; available in PMC 2019 October 01. 